\title{
Small Intestinal Bacterial Overgrowth and Irritable Bowel Syndrome: A Bridge between Functional Organic Dichotomy
}

\author{
Uday C. Ghoshal, Ratnakar Shukla, and Ujjala Ghoshal \\ Department of Gastroenterology and Microbiology, Sanjay Gandhi Postgraduate Institute of Medical Sciences, Lucknow, India
}

The pathogenesis of irritable bowel syndrome (IBS), once thought to be largely psychogenic in origin, is now understood to be multifactorial. One of the reasons for this paradigm shift is the realization that gut dysbiosis, including small intestinal bacterial overgrowth (SIBO), causes IBS symptoms. Between $4 \%$ and $78 \%$ of patients with IBS and $1 \%$ and $40 \%$ of controls have SIBO; such wide variations in prevalence might result from population differences, IBS diagnostic criteria, and, most importantly, methods to diagnose SIBO. Although quantitative jejunal aspirate culture is considered the gold standard for the diagnosis of SIBO, noninvasive hydrogen breath tests have been popular. Although the glucose hydrogen breath test is highly specific, its sensitivity is low; in contrast, the early-peak criteria in the lactulose hydrogen breath test are highly nonspecific. Female gender, older age, diarrhea-predominant IBS, bloating and flatulence, proton pump inhibitor and narcotic intake, and low hemoglobin are associated with SIBO among IBS patients. Several therapeutic trials targeting gut microbes using antibiotics and probiotics have further demonstrated that not all symptoms in patients with IBS originate in the brain but rather in the gut, providing support for the micro-organic basis of IBS. A recent proof-of-concept study showing the high frequency of symptom improvement in patients with IBS with SIBO further supports this hypothesis.(Gut Liver 2017;11:196-208)

Key Words: Bacterial overgrowth; Dysbiosis; Breath tests; Gastrointestinal microbiota; Probiotics; Rifaximin

\section{INTRODUCTION}

Irritable bowel syndrome (IBS) is one of the commonest disorders encountered in Gastroenterology practice. ${ }^{1}$ IBS is manifested by abdominal pain and/or discomfort, irregular stool form and passage. ${ }^{2}$ Bloating is another common symptom of IBS. ${ }^{2,3}$ Patients with small intestinal bacterial overgrowth (SIBO), in which there is increase in bacteria equal to or greater than $10^{5}$ colony forming unit per mL of upper gut aspirate, ${ }^{2}$ also experience abdominal pain or discomfort, bloating, flatulence and loose motion. ${ }^{4,5}$ In contrast to the earlier belief, SIBO is known to occur in absence of anatomical factors predisposing to it. ${ }^{6} \mathrm{~A}$ proportion of patients with IBS are known to have SIBO. ${ }^{7}$ Recent realization that SIBO may be associated with symptoms of IBS, led to a paradigm shift in understanding the pathogenesis of this condition, hitherto thought to be related largely to psychological factors, ${ }^{8}$ to more organic nature. ${ }^{7}$ Such realization is well known in other conditions as well; for example, peptic ulcer, once thought to be related to psychological stress, ${ }^{9}$ is now known to be related to infection with Helicobacter pylori. ${ }^{10,11}$ Hence, it is worthwhile reviewing the existing literature on SIBO and IBS.

\section{GUT FLORA AND SIBO}

Human gut harbor $10^{14}$ bacterial cells, which are 10 times higher than the number of cells in the human body. ${ }^{12}$ Gastrointestinal (GI) tract is considered as the most heavily colonized organ and more than 70\% of microbes reside in colon. ${ }^{13}$ The human GI tract is inhabited by a vast number of microbial population including bacteria, fungi, and viruses. ${ }^{14}$ Bacteria contribute to the largest population of gut microbiota, consisting of 500 (using culture approaches) to 1,000 (by 16S rRNA gene sequencing) different bacterial species. ${ }^{15}$ The number of bacteria increases from stomach $\left(10^{1}\right.$ to $10^{3}$ bacteria/g) to the colon $\left(10^{11}\right.$ to $10^{12}$ bacteria/g). ${ }^{13}$ The small intestine comprises mainly of Gram positive and aerobic bacteria and the large intestine contains predominantly Gram negative and anaerobic bacteria. ${ }^{16}$ Majority of bacteria residing in the colon are strictly

Correspondence to: Uday C. Ghoshal

Department of Gastroenterology, Sanjay Gandhi Postgraduate Institute of Medical Sciences, Raebareli Road, Lucknow 226014, India

Tel: +91-522-249-4405, Fax: +91-522-266-8017, E-mail: udayghoshal@gmail.com

Received on March 14, 2016. Revised on July 7, 2016. Accepted on July 11, 2016.

pISSN 1976-2283 eISSN 2005-1212 https://doi.org/10.5009/gnl16126

@) This is an Open Access article distributed under the terms of the Creative Commons Attribution Non-Commercial License (http://creativecommons.org/licenses/by-nc/4.0) which permits unrestricted non-commercial use, distribution, and reproduction in any medium, provided the original work is properly cited. 
anaerobes (95\% of total) followed by facultative anaerobes and aerobes. ${ }^{15}$ More than 50 bacterial phyla have been identified in human gut. ${ }^{17}$ Major phyla residing in the gut are Bacteroidetes and Firmicutes, whilst Proteobacteria, Verrucomicrobia, Actinobacteria, Fusobacteria, and Cyanobacteria are present in minor proportion. $^{13,18}$

Normal gut flora may provide several beneficial effects to the host. These include fermentation of un-digested dietary residue and endogenous mucus producing short chain fatty acids, which are nutrients to the colonic epithelial cells and conservation of energy, absorption of $\mathrm{NaCl}$ and water, particularly from the right colon, synthesis of vitamin $\mathrm{K}$, control of epithelial cell proliferation, protection against pathogens by a barrier effect and training of the immune system. ${ }^{19-21}$ One study showed that small intestine of germ free animal has thin and irregular villi, reduced crypt size, increased number of Peyer's patches, and infiltration of leukocytes in lamina propria. ${ }^{22,23}$ Alteration in the normal flora leads to disturbance in the intestinal homeostasis. ${ }^{2}$ There are several intrinsic and extrinsic factors that prevent overgrowth of bacteria in the small intestine. Intrinsic factors include: (1) secretion of gastric juice and bile, which have antibacterial effect; (2) peristaltic movement preventing adherence of bacteria into the intestinal mucosa; (3) normal gut defense including humoral and cellular mechanisms; (4) mucin production by intestinal mucosal epithelial cell inhibiting pathogenic bacteria; (5) gut antibacterial peptides such as defensins; and (6) ileocecal valve preventing retrograde translocation of bacteria from colon to the small intestine. ${ }^{24-26}$ Extrinsic factors include diet and drugs modulating gut flora, such as pre and probiotics, gastric acid suppressants such as proton pump inhibitors (PPIs), $\mathrm{H}_{2}$ blockers, and antibiotics and drugs altering motility (prokinetics, anticholinergics, and opioids). ${ }^{42,27-30}$ If, there is failure of any of the above-mentioned protective mechanisms, it may lead to development of SIBO (Fig. 1).

Though quantitative culture of the upper gut aspirate has traditionally been used as the gold standard for the diagnosis SIBO, its limitations include difficulty and invasiveness, cost, contamination by oropharyngeal flora, and inability to culture as high as 70\% bacteria colonizing the gut. ${ }^{2,13,30,31}$ Moreover, distribution of bacterial overgrowth may be patchy and upper gut aspirate may not be able to detect bacterial overgrowth in distal gut. ${ }^{30,32}$ The anaerobic bacteria may not grow if air is used during endoscopy; hence, either nitrogen or carbon dioxide is better for this purpose. In one of our earlier studies in which we used air during endoscopy, of 34 of 50 patients with malabsorption syndrome in whom bacteria were cultured in jejunal aspirate, only one grew anaerobic bacteria. ${ }^{33}$ Hence, search for other less invasive and patient-friendly methods for diagnosis of SIBO continues.

In an attempt to overcome some of the limitations of the traditional culture-based method for diagnosis of SIBO, a novel technology, called culturomics, has been developed recently. ${ }^{15}$
Culturomics confer a new platform for identification of large number of bacterial colonies as well as noncultivable species in a short time duration using matrix-assisted laser desorption ionization time-of-flight (MALDI-TOF) ${ }^{15,34}$ In a recent study, using 212 different culture conditions, 340 different bacterial, 5 fungal species and one virus were identified, including 31 new species using culturomics (MALDI-TOF) technique. ${ }^{34,35}$ Thus, culturomic approaches are feasible, rapid, cost-effective and reproducible for the study of gut microbiota. ${ }^{15,34}$ However, studies on SIBO using culturomics method are lacking. Moreover, use of effective culture conditions and sequencing methods may make it rarely usable for routine clinical application.

Breath tests are popular, noninvasive and patient-friendly methods used increasingly for diagnosis of SIBO ${ }^{36}$ Diagnostic role of hydrogen breath tests depends on the type of the substrates used; for example, lactose and fructose hydrogen breath tests are useful for carbohydrate malabsorption; on the other hand, glucose and lactulose hydrogen breath tests (GHBT and LHBT) are useful for diagnosis of SIBO, the former being more specific. Therefore, choice of the substrate while performing hydrogen breath test is important as only specific substrate diagnoses SIBO and others test for carbohydrate malabsorption. ${ }^{36}$ Hydrogen and methane gases are produced by the gut flora from the ingested substrates, particularly the colonic flora in patients with carbohydrate malabsorption and from small bowel bacteria in patients with SIBO. ${ }^{7,24,37}$ Eighty percent of the gases like hydrogen and methane are eliminated with the flatus and the remaining 20\% are absorbed and exhaled by lung, which can be measured in breath. ${ }^{22,38}$ In GHBT, rise in hydrogen by 12 parts per million (ppm) above basal following administration of 50 to $100 \mathrm{~g}$ glucose due to bacterial fermentation of the substrate in small intestine is diagnostic of SIBO. ${ }^{36}$ A recent study showed that measuring methane does not increase the yield of hydrogen breath test to diagnose SIBO.$^{39}$ In presence of SIBO, two peaks may be seen during LHBT: the first one due to bacterial fermentation of lactulose in small bowel and the second one after lactulose reaches colon. ${ }^{36}$ Since number of bacteria in colon is higher than that in the small bowel even in patients with SIBO, a rise in breath hydrogen more than 20 ppm above basal is expected from colonic fermentation of the lactulose. ${ }^{40}$ Though GHBT is highly specific (78\% to $97 \%),{ }^{41,42}$ it is quite insensitive (15.7\% to $62 \%) .{ }^{42,43}$ In contrast, conventional double-peak criteria on LHBT lack sensitivity (31\% to 68\%) and the recently proposed early-peak criterion (rise in breath hydrogen within 90 minutes by 20 ppm above basal following lactulose ingestion) often gives false positive result with specificity of 65\% to $97.9 \% .^{39,44}$ This is the reason for overestimation of frequency SIBO (as high as 78\%) in the initial studies from United States. ${ }^{40}$ In fact, the early-peak criterion on LHBT, which was used in the initial studies on SIBO in patients with IBS, presumed that normal mouth to cecum transit time is more than 90 minutes in spite of the observation that it may be shorter. ${ }^{36,40}$ A study that 


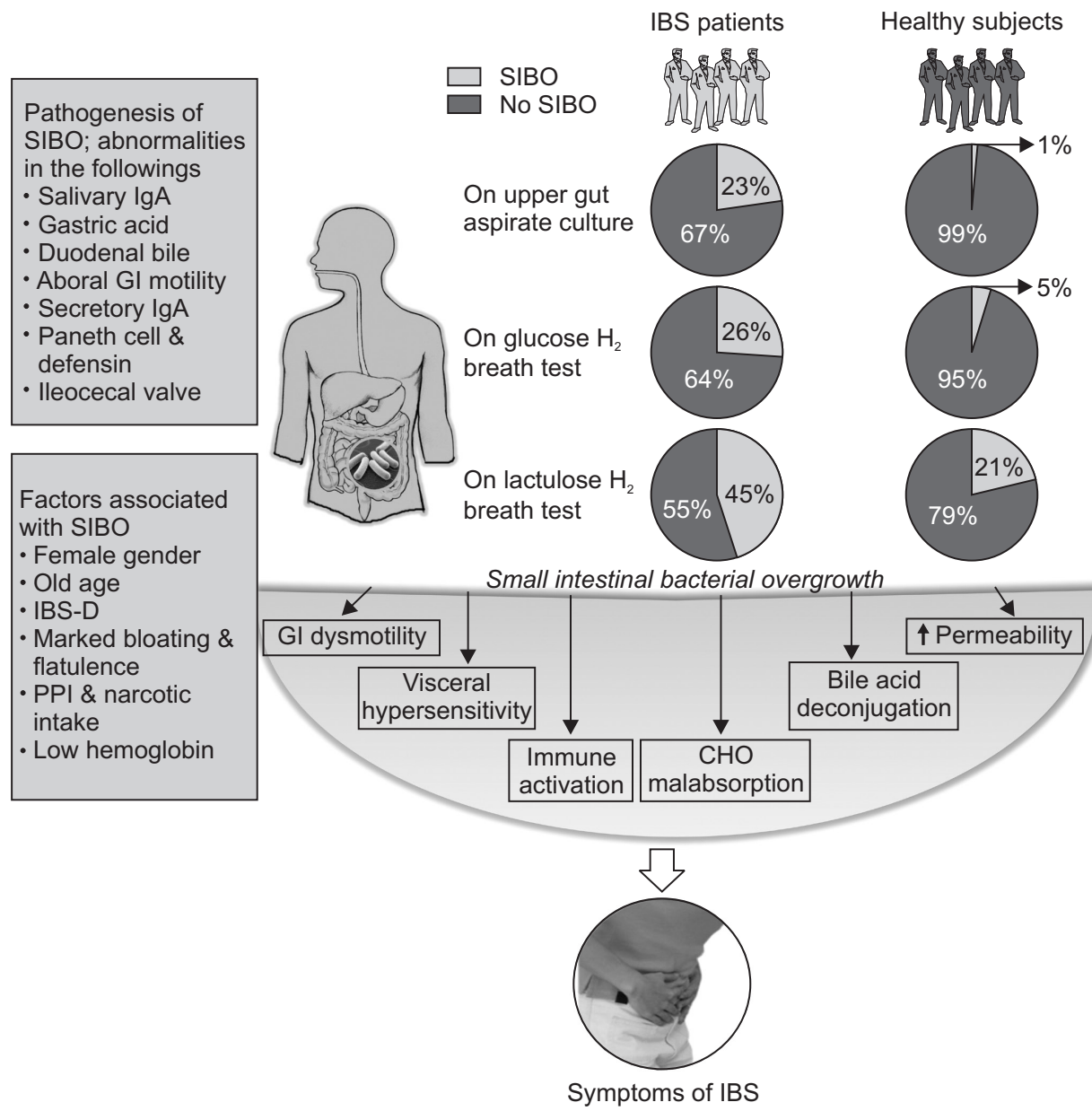

Fig. 1. Schematic diagram showing the frequency of small intestinal bacterial overgrowth (SIBO) using quantitative jejunal aspirate culture, glucose and lactulose hydrogen breath tests (GHBT and LHBT, respectively) among patients with irritable bowel syndrome (IBS), gut defense mechanisms that prevent the development of SIBO, factors associated with SIBO among patients with IBS, and mechanisms of IBS symptom development. As shown in the figure, the frequency of SIBO in IBS patients using LHBT (earlypeak criteria) is higher than that by using upper gut aspirate culture and GHBT (LHBT [45\%]; upper gut aspirate culture [23\%] and GHBT [26\%]). Moreover, SIBO is more frequent in healthy controls using LHBT due to false positive test results (LHBT [21\%], upper gut aspirate culture [1\%] and GHBT [5\%]).

GI, gastrointestinal; IBS-D, irritable bowel syndrome, diarrhea-predominan; PPI, proton pump inhibitor; CHO, carbohydrate. combined radio-nuclide gut transit and LHBT revealed that in most patients in whom a peak in hydrogen was seen on LHBT, radio-nuclide already arrived in cecum. ${ }^{45}$ Other methods for diagnosis of SIBO include $\mathrm{CO}_{2}$ breath tests $\left({ }^{14} \mathrm{C}\right.$ or ${ }^{13} \mathrm{C} \mathrm{D}$-xylose, ${ }^{13} \mathrm{C}$ glucose and ${ }^{13} \mathrm{C}$ cholyl-glycine hydrolase). ${ }^{7,22,46,47}$

Though hydrogen breath tests are quite popular for the diagnosis of SIBO, these are not free from limitations. In patients with distal SIBO, GHBT may be falsely negative as glucose gets completely absorbed in the proximal small bowel and hence, may not reach the site of SIB0, ${ }^{5,31,36}$ In patients with fast gut transit, early peak criteria proposed by Pimentel et al. ${ }^{40}$ often give false positive results. ${ }^{36}$ Fast gut transit is not uncommon, particularly in Asia. In a study from our center, median orocecal transit time in healthy subjects was 65 minutes (range, 40 to 110 minutes). ${ }^{48}$ A Taiwanese study revealed that average orocecal transit time was $85 \pm 37$ minutes. ${ }^{49}$ Hence, it is important to realize that there is need to search for a noninvasive yet sensitive and specific method for diagnosis of SIBO.

\section{FREQUENCY OF SIBO IN PATIENTS WITH IBS}

There are several studies evaluating frequency of SIBO among patients with IBS as compared with controls using different di- agnostic methods such as GHBT, LHBT and quantitative upper gut aspirate culture. ${ }^{7}$ Table 1 summarizes the results of these studies. As shown in the Table 1, frequency SIBO among patients with IBS ranged between 4\% and 78\% and that among controls, between 1\% and 40\%. ${ }^{37,39,40,45,50-68}$ Most case-control studies revealed that SIBO was commoner among IBS than controls; this suggests that there is significant association between SIBO and IBS (Fig. 1).

Two meta-analyses also suggested association between IBS and SIBO. In a meta-analysis by Ford et al., ${ }^{69}$ of the 12 studies including 1,921 patients with IBS, pooled prevalence of a positive LHBT and GHBT was 54\% (95\% confidence interval [CI], $32 \%$ to $76 \%$ ) and 31\% (95\% CI, 14\% to 50\%), respectively. The odds ratio (OR) for any test showing positive SIBO result among patients with IBS as compared to controls was 3.45 to $4.7 .^{69} \mathrm{In}$ another meta-analysis on 11 studies, breath testing was found to be abnormal among patients with IBS than controls (OR, 4.46; 95\% CI, 1.69 to 11.80). Breath testing had an overall sensitivity and specificity in separating IBS patients from healthy subjects of $44 \%$ and $84 \%$, respectively. ${ }^{42}$ However, in this meta-analysis, authors suggested that abnormal breath test might not always mean SIBO as rise in breath hydrogen greater than $20 \mathrm{ppm}$ above basal has poor specificity to diagnose SIBO. ${ }^{42}$ 
Table 1. Prevalence of Small Intestinal Bacterial Overgrowth among Patients with Irritable Bowel Syndrome

\begin{tabular}{|c|c|c|c|c|c|c|c|}
\hline Study no. & $\begin{array}{l}\text { Prevalence of } \\
\text { SIBO in cases }\end{array}$ & $\begin{array}{l}\text { Prevalence of } \\
\text { SIBO in } \\
\text { controls }\end{array}$ & $\begin{array}{l}\text { Methane } \\
\text { producers in } \\
\text { cases }\end{array}$ & $\begin{array}{l}\text { Methane } \\
\text { producers in } \\
\text { controls }\end{array}$ & Country & Year & Reference \\
\hline \multicolumn{8}{|c|}{ Culture of jejunal aspirate ( $\geq 10^{5} \mathrm{CFU} / \mathrm{mL}$ colonic-type bacteria) } \\
\hline 1 & $7 / 162(4)$ & $1 / 26(4)$ & ND & ND & Sweden & 2007 & Posserud et al..$^{52}$ \\
\hline 2 & $4 / 12(33)$ & $0 / 9$ & ND & ND & The Netherlands & 2008 & Kerckhoffs et al..$^{53}$ \\
\hline 3 & $15 / 80(18)$ & $0 / 10$ & 2/15 (13) & ND & India & 2014 & Ghoshal et al..$^{39}$ \\
\hline 4 & $42 / 112(37)$ & $\mathrm{ND}$ & ND & ND & Greece & 2012 & Pyleris et al..$^{54}$ \\
\hline \multicolumn{8}{|c|}{ Culture of jejunal aspirate ( $\geq 10^{3} \mathrm{CFU} / \mathrm{mL}$ colonic-type bacteria) } \\
\hline 5 & $62 / 139(44.6)$ & $\mathrm{ND}$ & $\mathrm{ND}$ & ND & United States & 2015 & Erdogan et al..$^{27}$ \\
\hline \multicolumn{8}{|c|}{ Lactulose hydrogen breath test } \\
\hline 6 & 157/202 (78) & ND & ND & ND & United States & 2000 & Pimentel et al. ${ }^{40}$ \\
\hline 7 & 64/98 (65) & ND & ND & ND & Italy & 2005 & Nucera et al. ${ }^{37}$ \\
\hline 8 & 39/390 (10) & ND & ND & ND & Canada & 2005 & Walters and Vanner ${ }^{55}$ \\
\hline 9 & 35/89 (39) & $1 / 13(8)$ & ND & ND & China & 2014 & Zhao et al. ${ }^{56}$ \\
\hline 10 & $25 / 40(63)$ & ND & ND & ND & Canada & 2011 & Yu et al. ${ }^{45}$ \\
\hline 11 & $34 / 76(45)$ & $16 / 40(40)$ & $19 / 76(25)$ & $10 / 40(25)$ & Korea & 2010 & Park et $a .^{57}$ \\
\hline 12 & $28 / 43(65)$ & $4 / 56(7)$ & $4 / 43(9)$ & 0 & Italy & 2009 & Scarpellini et al. ${ }^{58}$ \\
\hline 13 & $55 / 127(43)$ & $\mathrm{ND}$ & ND & ND & Italy & 2008 & Carrara et al. ${ }^{59}$ \\
\hline 14 & 89/258 (34.5) & ND & ND & ND & United States & 2009 & Mann and Limoges-Gonzales ${ }^{60}$ \\
\hline 15 & $60 / 175(34.3)$ & $45 / 150(30)$ & ND & ND & India & 2008 & Rana et al. ${ }^{61}$ \\
\hline 16 & 22/119 (18.4) & ND & ND & ND & Pakistan & 2011 & Yakoob et al. ${ }^{62}$ \\
\hline \multicolumn{8}{|c|}{ Glucose hydrogen breath test } \\
\hline 17 & 25/225 (11.1) & $1 / 100(1)$ & ND & ND & India & 2012 & Rana et al. ${ }^{67}$ \\
\hline 18 & 93/204 (46) & ND & 27/204 (13) & ND & United States & 2007 & Majewski and McCallum ${ }^{63}$ \\
\hline 19 & 105/331 (32) & $7 / 105(7)$ & ND & ND & Rome & 2014 & Moraru et al. ${ }^{70}$ \\
\hline 20 & $14 / 59(24)$ & $1 / 37(2.7)$ & $5 / 59(9)$ & 9/37 (24) & India & 2011 & Sachdeva et al. ${ }^{64}$ \\
\hline 21 & $11 / 129(8.5)$ & $1 / 51(2)$ & ND & ND & India & 2010 & Ghoshal et al. ${ }^{51}$ \\
\hline 22 & 44/96 (45.8) & ND & ND & ND & Italy & 2006 & Cuoco and Salvangnini $^{65}$ \\
\hline 23 & 20/65 (31) & 4/102 (4) & ND & ND & Italy & 2005 & Lupascu et al. ${ }^{66}$ \\
\hline 24 & 8/72 (11.1) & ND & ND & ND & Rome & 2013 & Moraru et al..$^{50}$ \\
\hline 25 & 49/200 (24.5) & 3/50 (6) & ND & ND & Italy & 2010 & Lombardo et al. ${ }^{143}$ \\
\hline 26 & 38/139 (27.3) & ND & ND & ND & United States & 2015 & Erdogan et $a l^{27}$ \\
\hline 27 & $11 / 175(6.2)$ & $1 / 150(0.66)$ & ND & ND & India & 2012 & Rana et al. ${ }^{97}$ \\
\hline 28 & 40/107 (37.3) & $14 / 107(13)$ & ND & ND & Iran & 2015 & Abbasi et $a .^{68}$ \\
\hline
\end{tabular}

Data are presented as number (\%).

SIBO, small intestinal bacterial overgrowth; CFU, colony forming unit; ND, not done.

In last half a decade, after these meta-analyses were published, at the time of writing this review, about eight case-control studies on frequency of SIBO among patients with IBS have been published (Table 1). Two of these studies were published from United States, three from India, one each from Pakistan, Romania, and Iran..$^{27,39,54,62,64,67,68,70}$ Of the five studies, which compared the frequency of SIBO among patients with IBS as compared to healthy controls, four showed significant difference. In these studies, frequency of SIBO among patients with IBS ranged between 19\% and 37\% and that among healthy controls between $0 \%$ and $12 \% .^{27,39,54,62,64,67,68,70}$ It is worthwhile evaluating the reasons for such wide variation in frequency of SIBO in these studies.

\section{EXPLANATION FOR DIFFERENCE IN PREVALENCE OF SIBO IN IBS}

Variations in prevalence of SIBO in patients with IBS and controls in several studies might be attributed to difference in geographical origin of studied population, different criteria for diagnosis of IBS (such as Manning, Rome I, II, and III), and methods for diagnosis of SIBO using different breath tests (such 
as nature of substrates, gases analyzed, instrument). ${ }^{51}$ Early peak criteria of LHBT give higher frequency of SIBO among patients with IBS and controls than other diagnostic methods, which might be attributed to false positive results. ${ }^{7,40,57,59,60}$ Whilst, double peak criteria on LHBT and GHBT give low frequency of SIBO in IBS patients and controls, which might be due to low sensitivity. ${ }^{7}$ Advanced noninvasive diagnostic techniques must be standardized for therapeutic management of SIBO in patients with IBS.

\section{FACTORS ASSOCIATED WITH SIBO AMONG PATIENTS WITH IBS}

There are several factors that are associated with SIBO among patients with IBS. These include female gender, older age, predominant symptom of bloating and flatulence, and diarrheal subtype of IBS.,71 In fact, in a recent study, we found that number of bacterial colonies in the small bowel influenced Bristol stool type with higher number being associated with looser stools. ${ }^{39}$ Similar observation has been reproduced in another recent study. ${ }^{72}$ Since many patients with IBS might be taking PPIs due to overlapping dyspepsia, and PPI intake may influence development of SIBO, this may be one factor predicting occurrence of SIBO among patients with IBS. ${ }^{4,73}$ Narcotic intake might be another factor causing SIBO among patients with IBS due to slowing of gut motility. ${ }^{74}$ In one study, we found that lower value hemoglobin was associated with SIBO on GHBT. ${ }^{51}$ Subjects with older age are more susceptible to SIBO, most likely as a result of reduced GI motility, intestinal surgery, small bowel diverticulosis and use of medications. ${ }^{75}$ One previous study reported that patients older than 55 years with symptoms of IBS, particularly abdominal bloating and flatulence were more likely to be positive by GHBT. ${ }^{4}$ Abdominal bloating among patients with IBS might be due to excess gas production by bacterial fermentation of undigested carbohydrates, in addition to SIBO. ${ }^{76}$

\section{MICROBIOLOGICAL ASPECTS OF SIBO IN IBS}

SIBO can be classified into two categories based on difference in bacterial flora: (1) Gram positive flora might be due to failure of gastric acid barrier, and (2) coliform bacteria might be due to failure of intestinal clearance and small bowel anatomical alterations. ${ }^{52,77}$ Recently, one study based on culture of jejunal aspirates showed that Pseudomonas aeruginosa, Escherichia coli, Acenetobacter lwoffii, Staphylococcus species, Klebsiella pneumoniae, Streptococcus species, Acinetobacter baumannii, Enterococcus faecalis, and Enterococcus faecium were dominant bacteria among patients with SIBO.$^{39}$ Pyleris et al..$^{54}$ reported that of 42/112 patients with IBS having SIBO, E. coli, Enterococcus species and K. pneumoniae were the predominant species. Gram negative bacilli and Enterobacter were most common on culture of jejunal aspirates among patients with IBS. ${ }^{54}$

\section{PATHOGENESIS OF IBS SYMPTOMS AMONG PATIENTS WITH SIBO}

Though the pathophysiology of IBS remains largely enigmatic, evidence from recent studies does show that dysbiosis may contribute to development of symptoms, at least in a subset of patients. ${ }^{2,78}$ Though SIBO is a form of quantitative alteration of small bowel microbes, altered microbiota (dysbiosis) does not necessarily mean SIBO only. Dysbiosis includes qualitative alteration of gut flora (most authors reported on fecal microbiota) but also its quantitative change (SIBO). ${ }^{79,80}$ In the recent Rome IV review, importance of dysbiosis including that of SIBO has been recognized by several experts. ${ }^{81-83}$ In SIBO, bacterial fermentation of diet in the lumen produces hydrogen, methane and carbon dioxide gases, which may contribute to symptoms like distension, flatulence, abdominal pain, and bloating., ${ }^{2,22}$ Methane is known to slow gut transit resulting in constipation. ${ }^{84}$ These gases, however, may also be produced in the colon among patients without SIBO in presence of carbohydrate malabsorption.

SIBO is more often associated with diarrhea than constipation-predominant IBS. ${ }^{7}$ Mechanism of diarrhea in patients with SIBO include de-conjugation of bile salts, enterotoxic effect of bacterial metabolites, increased small intestinal permeability, deficiency of vitamin $\mathrm{B}_{12}$ and low grade inflammation resulting from immune activation in the small intestinal mucosa. ${ }^{22,37,85}$

Secondary deficiency of disaccharidases (e.g., lactase) is well known in patients with SIBO.$^{86,87}$ This results in maldigestion of carbohydrates such as lactulose, sucrose and sorbitol. ${ }^{86,87}$ Moreover, fermentation of carbohydrates leads to formation of short chain fatty acids like acetic acid, propionic acid and butyric acid. $^{88}$ Though short chain fatty acids are useful for colon by providing nutrients to the colonocytes, conservation of energy and absorption of water and electrolytes, in the small bowel, it inhibits nutrient absorption and inhibits jejunal motility (ileal brake) through liberation of peptide YY, neurotensin and glucagon like peptide-1, which promotes SIBO.$^{89}$ Lipopolysaccharides derived from Gram negative bacteria may also affect the GI motility. ${ }^{90}$ Furthermore, bacterial derived metabolites may affect colonic motility. Likewise, formyl-methionyl-leucyl-phenylalanine may affect the enteric nervous system..$^{1-94}$

Bacteria utilize intraluminal proteins leading to production of ammonia. ${ }^{95}$ Bacterial overgrowth produces a number of toxic compounds (peptidoglycans, D-lactate and serum amyloid A), which promote inflammation, may damage the brush border of the enterocytes and increases small intestinal permeability. ${ }^{22,95}$ Host response to SIBO also depends on its genetic make-up as evidenced by a recent case-control study on 209 patients with IBS and 273 healthy subjects. ${ }^{96}$ Under-producer genotypes of interleukin 1 (IL-1) receptor antagonist gene (anti-inflammatory) were associated with IBS. ${ }^{96}$ Moreover, IBS patients had higher levels of IL-1 $\alpha$ and $\beta$ than those without SIBO. ${ }^{96}$ Another study showed higher level of proinflammatory cytokines such as IL-6 
and tumor necrosis factor $\alpha$ among patients with IBS-D than controls. ${ }^{97}$ In addition, SIBO is associated with increased level of serum endotoxins, inflammatory cytokines and chemokines, and endogenous production of ethanol. ${ }^{23,95,98}$

Increased number of enterochromaffin cells was found in the mucosa of colon and rectum among patients with IBS than healthy controls. ${ }^{99}$ Immune activation in response to SIBO recruits increased number of intraepithelial lymphocytes, mast cells and enterochromaffin cells. ${ }^{100}$ Moreover, mediators of host immune response trigger the enteric nervous system altering GI motility and visceral hypersensitivity, which are the major pathophysiological mechanisms of IBS. ${ }^{101}$

Overgrowth of sulfate reducing bacteria may play an important role in patients with IBS. ${ }^{102}$ An association was found between bacterial derived hydrogen sulfide $\left(\mathrm{H}_{2} \mathrm{~S}\right)$ and visceral hypersensitivity. ${ }^{103} \mathrm{H}_{2} \mathrm{~S}$ is known to act as gaseous neurotransmitters inducing the contraction of detrusor muscle in the urinary bladder. ${ }^{103}$ Recently, a study has shown that $\mathrm{H}_{2} \mathrm{~S}$ produced by sulphate reducing bacteria may play role in pathogenesis of SIBO. The author suggested that breath $\mathrm{H}_{2} \mathrm{~S}$ could be considered as potential noninvasive biomarker for diagnosis of SIBO among patients with IBS-D. ${ }^{104}$

Fibromyalgia, a condition associated with IBS, is also associated with SIBO.$^{99}$ A study by Pimental et al. ${ }^{105}$ showed that all 42 patients with fibromyalgia had positive LHBT. This percentage was significantly higher than the control population $(3 / 15$, $20 \%$ ). These data might suggest that somatic hypersensitivity is also influenced by altered gut flora.

\section{TREATMENT OF SIBO IN PATIENTS WITH IBS}

There are several approaches to treat SIBO among patients with IBS that include antibiotics, probiotics and prokinetics. ${ }^{106}$ Dietary manipulation has potential influence on the gut microbiota that may relieve some of the symptoms of SIBO. ${ }^{2,22,107}$ Recently, utility of therapeutic manipulation of gut flora using antibiotic and probiotic ${ }^{2}$ to treat IBS is being increasingly recognized and hence, worth reviewing.

\section{Antibiotics}

While choosing antibiotics, one should consider whether its antibacterial spectrum is broad including aerobes and anaerobes and absorption is poor reducing systemic side effects. ${ }^{108}$ Though in the past, tetracycline, doxycycline, co-trimoxazole, fluoroquinolones have all been used in the treatment of SIBO, ${ }^{109,110}$ in most of the recent studies among patients with IBS, rifaximin has been the preferred antibiotic (Table 2). ${ }^{52,108,111-114}$

Rifaximin is a semi-synthetic, nonabsorbable antimicrobial agent that acts against Gram positive and Gram negative aerobic and anaerobic bacteria. ${ }^{108}$ Pimentel et al. ${ }^{115}$ reported two identically designed, large, multicenter, double blind, placebocontrolled trials (TARGET 1 and TARGET 2) among patients

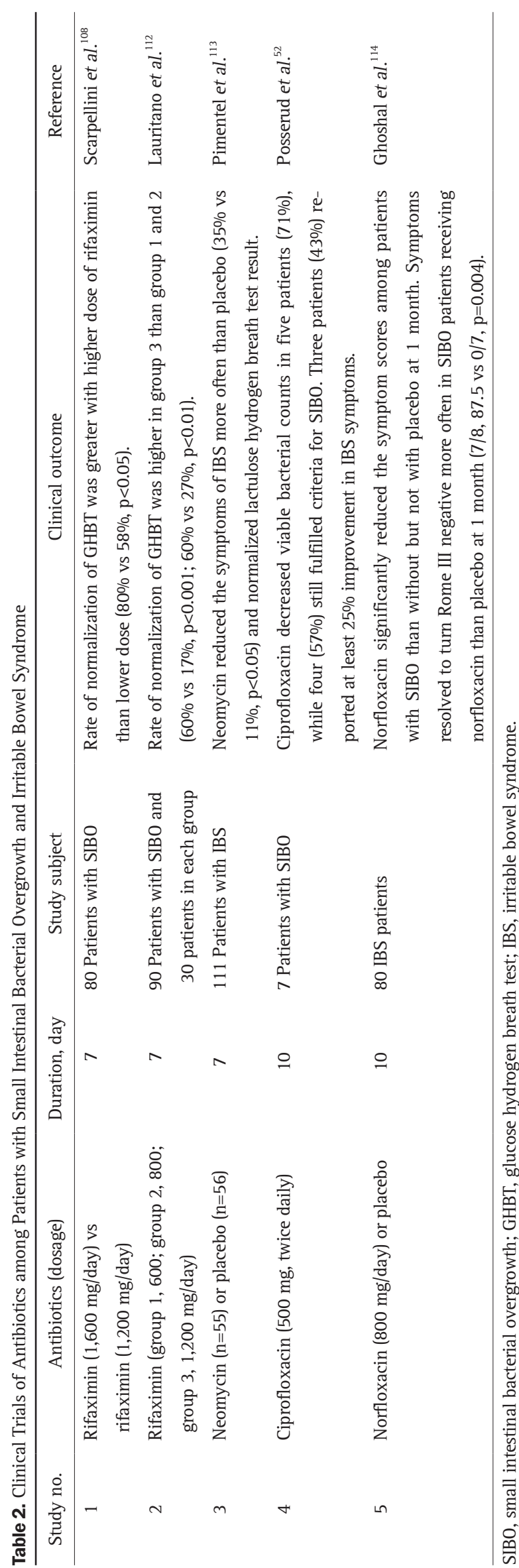


with nonconstipating IBS $(n=1,260)$ diagnosed by Rome II criteria. IBS subjects receiving rifaximin at a dose of $550 \mathrm{mg}$ three times daily for 14 days reported adequate relief in global IBS symptoms as compared to identical placebo (TARGET 1: 40.8\% vs $31.2 \%, \mathrm{p}=0.01$ and TARGET 2 : $40.6 \%$ vs $32.2 \%, \mathrm{p}=0.03) .{ }^{115}$ Moreover, rifaximin was more effective in relieving abdominal bloating than placebo (TARGET 1: 39.5\% vs 28.7\%, $\mathrm{p}=0.005$ and TARGET 2: $41.0 \%$ vs $31.9 \%, \mathrm{p}=0.02) .{ }^{115}$ The improvement in symptoms of IBS (like abdominal pain, loose or watery stool) persisted for a duration of 10 weeks after the end of 2-week treatment. $^{115}$

Recently, TARGET 3 study has been completed to evaluate the efficacy and safety of retreatment with rifaximin among 636 patients with IBS-D, who had responded to rifaximin previously but developed recurrent IBS symptoms over a duration of 18 weeks follow-up. ${ }^{116,117}$ The end-point of TARGET 3 study was different from the TARGET 1 and TARGET 2 studies according to the guidelines proposed by Food and Drug Administration (FDA). TARGET 3 study included those IBS subjects who reported improvement in symptoms during at least 2 of the first 4 weeks in abdominal pain ( $\geq 30 \%$ decrease from baseline in mean weekly pain score) and stool consistency ( $\geq 50 \%$ decrease from baseline in the number of days per week with bowel movements complying with type 6 or 7 on the Bristol stool form scale). ${ }^{117,118}$ Retreatment with rifaximin showed 33\% response rate as compared to $25 \%$ in placebo group ( $\mathrm{p}=0.02$ ), consistent with FDA guidelines for clinical assessment of IBS drugs. ${ }^{118}$

In a study of open level antibiotic treatment, bacterial overgrowth was eradicated in 25 out of 47 patients and symptoms of IBS like diarrhea and abdominal pain were improved. ${ }^{40}$ Moreover, $48 \%$ of the subjects were found negative for Rome I criteria. ${ }^{40}$ In another study, of the 10 patients with SIBO treated with norfloxacin, amoxicillin-clavulanic acid and Saccharomyces boulardii over a period of 7 days, ${ }^{119}$ norfloxacin and amoxicillin-clavulanic acid significantly improved the mean daily stool frequency, but not $S$. boulardii. ${ }^{119}$ Recently, a proof of the concept study suggested that the lower response rate of 40\% among patients treated with antibiotic in TARGET I and II studies might be related to the fact that patients were not selected based on the presence or absence of SIBO. In this study, 7 of $8(87.5 \%)$ of 15 patients with SIBO treated with norfloxacin became Rome III negative at 1 month as compared to none of those treated with placebo. Interestingly, in this study, of 40 patients treated with norfloxacin, 15 (37.5\%) responded showing that when not selected according to presence of SIBO, response rate was somewhat similar to the frequency of improvement as reported in TARGET I and II study. ${ }^{114}$

In a recent meta-analysis, efficiency of rifaximin (two studies) in eradicating SIBO was $64.1 \%$ as compared to $41 \%$ with other systemic antibiotics (metronidazole or tetracycline, $\mathrm{p}=0.003$ ). ${ }^{120}$ Another meta-analysis of eight studies showed that overall normalization rate of breath test with rifaximin was 49.5\% (95\%
CI, 44.0 to 55.1). ${ }^{121}$ Antibiotics like metronidazole, neomycin and ciprofloxacin (four studies) showed higher response rate than placebo in normalizing breath tests with an odds ratio of 2.55 (95\% CI, 1.29 to 5.04). ${ }^{121}$ Thus, evidence from above studies suggests that antibiotics can be given in IBS patients with suspected SIBO.

\section{Probiotics}

Probiotics are live microorganisms, which, when administered in sufficient quantities may alleviate symptoms of IBS than placebo as shown by several clinical trials. ${ }^{2}$ Probiotics may work by suppressing proinflammatory cytokines, modulating gut microbiota, sustaining the integrity of intestinal epithelium and altering the visceral hypersensitivity and brain function. ${ }^{28,122-125}$ Randomized controlled trials of probiotics among patients with SIBO are scanty. An old randomized controlled cross-over study only on 10 patients with SIBO showed that though norfloxacin and amoxicillin-clavulanic acid were effective in improving mean daily stool frequency and breath hydrogen, $S$. boulardii administered for one week was ineffective. ${ }^{119}$ Another study, however, showed that administration of high doses of $S$. boulardii for one month reduced abdominal pain, bloating, flatulence among pediatric patients with short bowel syndrome (SBS) and led to some change in bacterial flora in the stool samples suggesting that $S$. boulardii may impact the gut microbiota in patients with SBS. ${ }^{126}$ Furthermore, probiotics may enhance the efficiency of antibiotics. One study showed that treatment with rifaximin along with probiotic (Lactobacillus casei) improved the symptoms of SIBO more effectively than antibiotic followed by prebiotic (short chain fructo-oligosaccharide). ${ }^{127}$ Some studies recommended that treatment with rifaximin along with probiotics as a standard therapy for management of SIBO.$^{127}$ Use of multispecies probiotics had shown several benefits in reliving symptoms of IBS. ${ }^{128}$ A randomized controlled trial of VSL\#3 (twice daily for 8 weeks) in patients with IBS-D showed that abdominal bloating was significantly reduced as compared to placebo but not other parameters such as bowel dysfunction, colonic transit time, abdominal pain, flatulence or urgency. ${ }^{128,129}$ More studies, however, are needed to evaluate efficacy of probiotics among patients with IBS in relation to presence of SIBO.

\section{Prokinetics}

Since IBS is associated with alteration and gut motility, and SIBO is associated with motility disorders, prokinetics are expected to be beneficial in patients with SIBO. In an earlier study, Pimentel et al. ${ }^{130}$ showed that IBS patients with SIBO had lower frequency of migratory motor complex. Hence, it is expected that prokinetic drugs that improve small bowel motility might be useful in preventing SIBO following its successful treatment. The same group of authors showed that tegaserod, a serotonin receptor agonist, prevents the recurrence of IBS symptoms after antibiotic treatment compared to another prokinetic, erythro- 
mycin (a motilin agonist). ${ }^{131}$

\section{Dietary manipulation of gut microbiota}

Dietary manipulation may help patients with IBS in general and those with SIBO in particular. ${ }^{132,133}$ In patients with SIBO, bacteria in the small bowel may ferment carbohydrates such as lactose, fructose and also the dietary fermentable oligo-, di-, monosaccharides and polyols (FODMAPs), which forms gas resulting in flatulence, abdominal bloating and pain. ${ }^{134,135}$ Hence, restriction of these dietary components may improve these symptoms. ${ }^{136}$ Moreover, some preliminary data suggest that manipulation of the diet may alter gut microbiota. ${ }^{136}$ In a study, human fecal microbiota was transplanted into germ free mice that were fed low fat diet and plant polysaccharides. ${ }^{137}$ Subsequently, feeding Western diet resulted in change in composition of gut microbiota leading to increased number of Firmicutes, Clostridium species, Eubacterium, Enterococcus and decreased number of Bacteroides. ${ }^{137}$ Moreover, diet rich in complex carbohydrates favors growth of less pathogenic bacteria (Mycobacterium avium subspecies paratuberculosis and Enterobacteriaceae) than diet rich in fat or protein. ${ }^{138}$ Vegetarian diets, rich in fiber, lead to higher production of short chain fatty acids, which inhibit potentially invasive bacteria like $E$. coli and other members of Enterobacteriaceae. ${ }^{138,139}$ In a recent study, we found that vegetarianism was a risk factor for IBS on univariate and multivariate analysis. ${ }^{140}$ More studies are needed to evaluate effect of dietary manipulation on gut microbiota including SIBO.

\section{CONCLUSIONS}

Recent realization that SIBO play an important role in pathogenesis of symptoms in a subset of patients with IBS led to a paradigm shift in understanding this disorder, hitherto thought to be predominantly psychogenic in nature. This is further substantiated by the initiative of Rome Foundation that introduced the concept of multidimensional clinical profile in diagnosis and management of functional GI disorders including IBS. ${ }^{141}$ Though frequency of SIBO among patients with IBS varied between $4 \%$ and $78 \%$ patients, most studies reported the frequency to be higher among IBS than controls. Variation in the methods to diagnose SIBO is the most important reason for the wide variation in frequency of SIBO among patients with IBS in different studies. Quantitative jejunal aspirate culture, considered as the gold standard for the diagnosis of SIBO, is invasive and hence, hydrogen breath tests have been popularly used to diagnose SIBO.$^{31,142}$ However, whereas GHBT is highly specific, it is quite insensitive. On the other hand, the early-peak criteria in LHBT is highly nonspecific. ${ }^{36}$ Hence, clinical phenotype of IBS may be used to consider treating patients empirically for possible SIBO. Diarrhea-predominant IBS (looser stool on Bristol scale), marked bloating and flatulence, older age, symptom development while on PPI therapy have been shown to be associated with SIBO among patients with $\mathrm{IBS}^{143}$; unless better noninvasive methods for diagnosis of SIBO become available, patients with these clinical predictors may be treated for possible SIBO. Currently, rifaximin is the best treatment for SIBO among patients with IBS.

\section{CONFLICTS OF INTEREST}

No potential conflict of interest relevant to this article was reported.

\section{REFERENCES}

1. Wall GC, Bryant GA, Bottenberg MM, Maki ED, Miesner AR. Irritable bowel syndrome: a concise review of current treatment concepts. World J Gastroenterol 2014;20:8796-8806.

2. Ghoshal UC, Shukla R, Ghoshal U, Gwee KA, Ng SC, Quigley EM. The gut microbiota and irritable bowel syndrome: friend or foe? Int J Inflam 2012;2012:151085.

3. Malinen E, Krogius-Kurikka L, Lyra A, et al. Association of symptoms with gastrointestinal microbiota in irritable bowel syndrome. World J Gastroenterol 2010;16:4532-4540.

4. Reddymasu SC, Sostarich S, McCallum RW. Small intestinal bacterial overgrowth in irritable bowel syndrome: are there any predictors? BMC Gastroenterol 2010;10:23.

5. Lin HC. Small intestinal bacterial overgrowth: a framework for understanding irritable bowel syndrome. JAMA 2004;292:852858.

6. Dukowicz AC, Lacy BE, Levine GM. Small intestinal bacterial overgrowth: a comprehensive review. Gastroenterol Hepatol (N Y) 2007;3:112-122.

7. Ghoshal UC, Srivastava D. Irritable bowel syndrome and small intestinal bacterial overgrowth: meaningful association or unnecessary hype. World J Gastroenterol 2014;20:2482-2491.

8. Grover M, Kanazawa M, Palsson OS, et al. Small intestinal bacterial overgrowth in irritable bowel syndrome: association with colon motility, bowel symptoms, and psychological distress. Neurogastroenterol Motil 2008;20:998-1008.

9. Levenstein S, Rosenstock S, Jacobsen RK, Jorgensen T. Psychological stress increases risk for peptic ulcer, regardless of Helicobacter pylori infection or use of nonsteroidal anti-inflammatory drugs. Clin Gastroenterol Hepatol 2015;13:498-506.e1.

10. Safavi M, Sabourian R, Foroumadi A. Treatment of Helicobacter pylori infection: current and future insights. World J Clin Cases 2016;4:5-19.

11. Wang L, Tan RZ, Chen Y, et al. CagA promotes proliferation and secretion of extracellular matrix by inhibiting signaling pathway of apoptosis in rat glomerular mesangial cells. Ren Fail 2016;38:458-464.

12. Gerritsen J, Smidt H, Rijkers GT, de Vos WM. Intestinal microbiota in human health and disease: the impact of probiotics. Genes Nutr 2011;6:209-240. 
13. Sekirov I, Russell SL, Antunes LC, Finlay BB. Gut microbiota in health and disease. Physiol Rev 2010;90:859-904.

14. Ghoshal UC, Park H, Gwee KA. Bugs and irritable bowel syndrome: the good, the bad and the ugly. J Gastroenterol Hepatol 2010;25:244-251.

15. Lagier JC, Million M, Hugon P, Armougom F, Raoult D. Human gut microbiota: repertoire and variations. Front Cell Infect Microbiol 2012;2:136.

16. Nigam D. Microbial interactions with humans and animals. Int $\mathrm{J}$ Microbiol Allied Sci 2015;2:1-17.

17. Eckburg PB, Bik EM, Bernstein CN, et al. Diversity of the human intestinal microbial flora. Science 2005;308:1635-1638.

18. Schloss PD, Handelsman J. Status of the microbial census. Microbiol Mol Biol Rev 2004;68:686-691.

19. O'Hara AM, Shanahan F. The gut flora as a forgotten organ. EMBO Rep 2006;7:688-693.

20. Vyas U, Ranganathan N. Probiotics, prebiotics, and synbiotics: gut and beyond. Gastroenterol Res Pract 2012;2012:872716.

21. Goulet 0, Joly F. Intestinal microbiota in short bowel syndrome. Gastroenterol Clin Biol 2010;34 Suppl 1:S37-S43.

22. Bures J, Cyrany J, Kohoutova D, et al. Small intestinal bacterial overgrowth syndrome. World J Gastroenterol 2010;16:29782990.

23. Vanderhoof JA, Young RJ. Etiology and pathogenesis of bacterial overgrowth. Clinical manifestations and diagnosis of bacterial overgrowth: treatment of bacterial overgrowth. UpToDate Online 2010;18.

24. Gabrielli M, D’Angelo G, Di Rienzo T, Scarpellini E, Ojetti V. Diagnosis of small intestinal bacterial overgrowth in the clinical practice. Eur Rev Med Pharmacol Sci 2013;17 Suppl 2:30-35.

25. Hao WL, Lee YK. Microflora of the gastrointestinal tract: a review. Methods Mol Biol 2004;268:491-502.

26. Riordan SM, McIver CJ, Wakefield D, Duncombe VM, Thomas MC, Bolin TD. Small intestinal mucosal immunity and morphometry in luminal overgrowth of indigenous gut flora. Am J Gastroenterol 2001;96:494-500.

27. Erdogan A, Rao SS, Gulley D, Jacobs C, Lee YY, Badger C. Small intestinal bacterial overgrowth: duodenal aspiration vs glucose breath test. Neurogastroenterol Motil 2015;27:481-489.

28. Chey WD, Maneerattaporn M, Saad R. Pharmacologic and complementary and alternative medicine therapies for irritable bowel syndrome. Gut Liver 2011;5:253-266.

29. Peralta S, Cottone C, Doveri T, Almasio PL, Craxi A. Small intestine bacterial overgrowth and irritable bowel syndrome-related symptoms: experience with rifaximin. World J Gastroenterol 2009;15:2628-2631.

30. Ziegler TR, Cole CR. Small bowel bacterial overgrowth in adults: a potential contributor to intestinal failure. Curr Gastroenterol Rep 2007;9:463-467.

31. Ghoshal UC, Ghoshal U, Das K, Misra A. Utility of hydrogen breath tests in diagnosis of small intestinal bacterial overgrowth in malabsorption syndrome and its relationship with oro-cecal transit time. Indian J Gastroenterol 2006;25:6-10.

32. Britton E, McLaughlin JT. Ageing and the gut. Proc Nutr Soc 2013;72:173-177.

33. Ghoshal U, Ghoshal UC, Ranjan P, Naik SR, Ayyagari A. Spectrum and antibiotic sensitivity of bacteria contaminating the upper gut in patients with malabsorption syndrome from the tropics. BMC Gastroenterol 2003;3:9.

34. Lagier JC, Armougom F, Million M, et al. Microbial culturomics: paradigm shift in the human gut microbiome study. Clin Microbiol Infect 2012;18:1185-1193.

35. Kokcha S, Mishra AK, Lagier JC, et al. Non contiguous-finished genome sequence and description of Bacillus timonensis sp. nov. Stand Genomic Sci 2012;6:346-355.

36. Ghoshal UC. How to interpret hydrogen breath tests. J Neurogastroenterol Motil 2011;17:312-317.

37. Nucera G, Gabrielli M, Lupascu A, et al. Abnormal breath tests to lactose, fructose and sorbitol in irritable bowel syndrome may be explained by small intestinal bacterial overgrowth. Aliment Pharmacol Ther 2005;21:1391-1395.

38. Abraczinskas D, Goldfinger SE. Intestinal gas and bloating. UpToDate Online 2010;18.

39. Ghoshal UC, Srivastava D, Ghoshal U, Misra A. Breath tests in the diagnosis of small intestinal bacterial overgrowth in patients with irritable bowel syndrome in comparison with quantitative upper gut aspirate culture. Eur J Gastroenterol Hepatol 2014;26:753760.

40. Pimentel M, Chow EJ, Lin HC. Eradication of small intestinal bacterial overgrowth reduces symptoms of irritable bowel syndrome. Am J Gastroenterol 2000;95:3503-3506.

41. Kerlin P, Wong L. Breath hydrogen testing in bacterial overgrowth of the small intestine. Gastroenterology 1988;95:982-988.

42. Shah ED, Basseri RJ, Chong K, Pimentel M. Abnormal breath testing in IBS: a meta-analysis. Dig Dis Sci 2010;55:2441-2449.

43. Simrén M, Stotzer PO. Use and abuse of hydrogen breath tests. Gut 2006;55:297-303.

44. Ojetti V, Di Rienzo TA, D’Angelo G, et al. Early peak of hydrogen during lactose breath test predicts intestinal motility. Open J Gastroenterol 2014;4:40-44.

45. Yu D, Cheeseman F, Vanner S. Combined oro-caecal scintigraphy and lactulose hydrogen breath testing demonstrate that breath testing detects oro-caecal transit, not small intestinal bacterial overgrowth in patients with IBS. Gut 2011;60:334-340.

46. Santavirta J. Lactulose hydrogen and [14C]xylose breath tests in patients with ileoanal anastomosis. Int J Colorectal Dis 1991;6:208-211.

47. Banik GD, Maity A, Som S, et al. Diagnosis of small intestinal bacterial overgrowth in irritable bowel syndrome patients using high-precision stable 13 CO 2/12 CO 2 isotope ratios in exhaled breath. J Anal At Spectrom 2014;29:1918-1924.

48. Ghoshal UC, Ghoshal U, Ayyagari A, et al. Tropical sprue is associated with contamination of small bowel with aerobic bacteria and reversible prolongation of orocecal transit time. J Gastroen- 
terol Hepatol 2003;18:540-547.

49. Lu CL, Chen CY, Chang FY, Lee SD. Characteristics of small bowel motility in patients with irritable bowel syndrome and normal humans: an Oriental study. Clin Sci (Lond) 1998;95:165-169.

50. Moraru IG, Portincasa P, Moraru AG, Diculescu M, Dumitraşcu DL. Small intestinal bacterial overgrowth produces symptoms in irritable bowel syndrome which are improved by rifaximin: a pilot study. Rom J Intern Med 2013;51:143-147.

51. Ghoshal UC, Kumar S, Mehrotra M, Lakshmi C, Misra A. Frequency of small intestinal bacterial overgrowth in patients with irritable bowel syndrome and chronic non-specific diarrhea. J Neurogastroenterol Motil 2010;16:40-46.

52. Posserud I, Stotzer P0, Björnsson ES, Abrahamsson H, Simrén M. Small intestinal bacterial overgrowth in patients with irritable bowel syndrome. Gut 2007;56:802-808.

53. Kerckhoffs AP, Visser MR, Samsom M, et al. Critical evaluation of diagnosing bacterial overgrowth in the proximal small intestine. J Clin Gastroenterol 2008;42:1095-1102.

54. Pyleris E, Giamarellos-Bourboulis EJ, Tzivras D, Koussoulas V, Barbatzas C, Pimentel M. The prevalence of overgrowth by aerobic bacteria in the small intestine by small bowel culture: relationship with irritable bowel syndrome. Dig Dis Sci 2012;57:1321-1329.

55. Walters B, Vanner SJ. Detection of bacterial overgrowth in IBS using the lactulose $\mathrm{H} 2$ breath test: comparison with 14C-D-xylose and healthy controls. Am J Gastroenterol 2005;100:1566-1570.

56. Zhao J, Zheng X, Chu H, et al. A study of the methodological and clinical validity of the combined lactulose hydrogen breath test with scintigraphic oro-cecal transit test for diagnosing small intestinal bacterial overgrowth in IBS patients. Neurogastroenterol Motil 2014;26:794-802.

57. Park JS, Yu JH, Lim HC, et al. Usefulness of lactulose breath test for the prediction of small intestinal bacterial overgrowth in irritable bowel syndrome. Korean J Gastroenterol 2010;56:242-248.

58. Scarpellini E, Giorgio V, Gabrielli M, et al. Prevalence of small intestinal bacterial overgrowth in children with irritable bowel syndrome: a case-control study. J Pediatr 2009;155:416-420.

59. Carrara M, Desideri S, Azzurro M, et al. Small intestine bacterial overgrowth in patients with irritable bowel syndrome. Eur Rev Med Pharmacol Sci 2008;12:197-202.

60. Mann NS, Limoges-Gonzales M. The prevalence of small intestinal bacterial overgrowth in irritable bowel syndrome. Hepatogastroenterology 2009;56:718-721.

61. Rana SV, Sinha SK, Sikander A, Bhasin DK, Singh K. Study of small intestinal bacterial overgrowth in North Indian patients with irritable bowel syndrome: a case control study. Trop Gastroenterol 2008;29:23-25.

62. Yakoob J, Abbas Z, Khan R, Hamid S, Awan S, Jafri W. Small intestinal bacterial overgrowth and lactose intolerance contribute to irritable bowel syndrome symptomatology in Pakistan. Saudi J Gastroenterol 2011;17:371-375.

63. Majewski M, McCallum RW. Results of small intestinal bacterial overgrowth testing in irritable bowel syndrome patients: clinical profiles and effects of antibiotic trial. Adv Med Sci 2007;52:139142.

64. Sachdeva S, Rawat AK, Reddy RS, Puri AS. Small intestinal bacterial overgrowth (SIBO) in irritable bowel syndrome: frequency and predictors. J Gastroenterol Hepatol 2011;26 Suppl 3:135-138.

65. Cuoco L, Salvagnini M. Small intestine bacterial overgrowth in irritable bowel syndrome: a retrospective study with rifaximin. Minerva Gastroenterol Dietol 2006;52:89-95.

66. Lupascu A, Gabrielli M, Lauritano EC, et al. Hydrogen glucose breath test to detect small intestinal bacterial overgrowth: a prevalence case-control study in irritable bowel syndrome. Aliment Pharmacol Ther 2005;22:1157-1160.

67. Rana SV, Sharma S, Kaur J, Sinha SK, Singh K. Comparison of lactulose and glucose breath test for diagnosis of small intestinal bacterial overgrowth in patients with irritable bowel syndrome. Digestion 2012;85:243-247.

68. Abbasi MH, Zahedi M, Darvish Moghadam S, Shafieipour S, HayatBakhsh Abbasi M. Small bowel bacterial overgrowth in patients with irritable bowel syndrome: the first study in iran. Middle East J Dig Dis 2015;7:36-40.

69. Ford AC, Spiegel BM, Talley NJ, Moayyedi P. Small intestinal bacterial overgrowth in irritable bowel syndrome: systematic review and meta-analysis. Clin Gastroenterol Hepatol 2009;7:12791286.

70. Moraru IG, Moraru AG, Andrei M, et al. Small intestinal bacterial overgrowth is associated to symptoms in irritable bowel syndrome: evidence from a multicentre study in Romania. Rom J Intern Med 2014;52:143-150.

71. Singh VV, Toskes PP. Small bowel bacterial overgrowth: presentation, diagnosis, and treatment. Curr Treat Options Gastroenterol 2004;7:19-28.

72. Vandeputte D, Falony G, Vieira-Silva S, Tito RY, Joossens M, Raes J. Stool consistency is strongly associated with gut microbiota richness and composition, enterotypes and bacterial growth rates. Gut 2016;65:57-62.

73. Spiegel BM, Chey WD, Chang L. Bacterial overgrowth and irritable bowel syndrome: unifying hypothesis or a spurious consequence of proton pump inhibitors? Am J Gastroenterol 2008;103:29722976.

74. Choung RS, Ruff KC, Malhotra A, et al. Clinical predictors of small intestinal bacterial overgrowth by duodenal aspirate culture. Aliment Pharmacol Ther 2011;33:1059-1067.

75. Gasbarrini A, Scarpellini E, Gabrielli M, Tortora A, Purchiaroni F, Ojetti V. Clinical predictors of small intestinal bacterial overgrowth by duodenal aspirate culture. Aliment Pharmacol Ther 2011;33:1378-1379.

76. Haderstorfer B, Psycholgin D, Whitehead WE, Schuster MM. Intestinal gas production from bacterial fermentation of undigested carbohydrate in irritable bowel syndrome. Am J Gastroenterol 1989;84:375-378.

77. Sachdev AH, Pimentel M. Gastrointestinal bacterial overgrowth: 
pathogenesis and clinical significance. Ther Adv Chronic Dis 2013;4:223-231.

78. Shukla R, Ghoshal U, Dhole TN, Ghoshal UC. Fecal microbiota in patients with irritable bowel syndrome compared with healthy controls using real-time polymerase chain reaction: an evidence of dysbiosis. Dig Dis Sci 2015;60:2953-2962.

79. Park $\mathrm{H}$. The role of small intestinal bacterial overgrowth in the pathophysiology of irritable bowel syndrome. J Neurogastroenterol Motil 2010;16:3-4.

80. Choi CH, Chang SK. Role of small intestinal bacterial overgrowth in functional gastrointestinal disorders. J Neurogastroenterol Motil 2016;22:3-5.

81. Barbara G, Feinle-Bisset C, Ghoshal UC, et al. The intestinal microenvironment and functional gastrointestinal disorders. Gastroenterology 2016;150:1305-1318.e8.

82. Francisconi CF, Sperber AD, Fang X, et al. Multicultural aspects in functional gastrointestinal disorders (FGIDs). Gastroenterology 2016;150:1344-1354.

83. Lacy BE, Mearin F, Chang L, et al. Bowel disorders. Gastroenterology 2016;150:1393-1407.

84. Pimentel M, Gunsalus RP, Rao SS, Zhang H. Methanogens in human health and disease. Am J Gastroenterol Suppl 2012;1:28-33.

85. Fan X, Sellin JH. Review article: small intestinal bacterial overgrowth, bile acid malabsorption and gluten intolerance as possible causes of chronic watery diarrhoea. Aliment Pharmacol Ther 2009;29:1069-1077.

86. Riepe SP, Goldstein J, Alpers DH. Effect of secreted Bacteroides proteases on human intestinal brush border hydrolases. J Clin Invest 1980;66:314-322.

87. Zaidel 0, Lin HC. Uninvited guests: the impact of small intestinal bacterial overgrowth on nutritional status. Pract Gastroenterol 2003;27:27-34.

88. Bala L, Ghoshal UC, Ghoshal U, et al. Malabsorption syndrome with and without small intestinal bacterial overgrowth: a study on upper-gut aspirate using 1H NMR spectroscopy. Magn Reson Med 2006;56:738-744.

89. Ghoshal UC, Kumar S, Misra A, Choudhuri G. Pathogenesis of tropical sprue: a pilot study of antroduodenal manometry, duodenocaecal transit time \& fat-induced ileal brake. Indian J Med Res 2013;137:63-72.

90. Donowitz JR, Petri WA Jr. Pediatric small intestine bacterial overgrowth in low-income countries. Trends Mol Med 2015;21:6-15.

91. Rhee SH, Pothoulakis C, Mayer EA. Principles and clinical implications of the brain-gut-enteric microbiota axis. Nat Rev Gastroenterol Hepatol 2009;6:306-314.

92. Malbert $\mathrm{CH}$. The ileocolonic sphincter. Neurogastroenterol Motil 2005;17 Suppl 1:41-49.

93. Dass NB, John AK, Bassil AK, et al. The relationship between the effects of short-chain fatty acids on intestinal motility in vitro and GPR43 receptor activation. Neurogastroenterol Motil 2007;19:66-74.

94. Barbara G, Stanghellini V, Brandi G, et al. Interactions between commensal bacteria and gut sensorimotor function in health and disease. Am J Gastroenterol 2005;100:2560-2568.

95. Dibaise JK, Young RJ, Vanderhoof JA. Enteric microbial flora, bacterial overgrowth, and short-bowel syndrome. Clin Gastroenterol Hepatol 2006;4:11-20.

96. Srivastava D, Ghoshal U, Mittal RD, Ghoshal UC. Associations between IL-1RA polymorphisms and small intestinal bacterial overgrowth among patients with irritable bowel syndrome from India. Neurogastroenterol Motil 2014;26:1408-1416.

97. Rana SV, Sharma S, Sinha SK, Parsad KK, Malik A, Singh K. Pro-inflammatory and anti-inflammatory cytokine response in diarrhoea-predominant irritable bowel syndrome patients. Trop Gastroenterol 2012;33:251-256.

98. Spinucci G, Guidetti M, Lanzoni E, Pironi L. Endogenous ethanol production in a patient with chronic intestinal pseudo-obstruction and small intestinal bacterial overgrowth. Eur J Gastroenterol Hepatol 2006;18:799-802.

99. Schmulson M, Bielsa MV, Carmona-Sánchez R, et al. Microbiota, gastrointestinal infections, low-grade inflammation, and antibiotic therapy in irritable bowel syndrome: an evidence-based review. Rev Gastroenterol Mex 2014;79:96-134.

100. Ford AC, Talley NJ. Mucosal inflammation as a potential etiological factor in irritable bowel syndrome: a systematic review. J Gastroenterol 2011;46:421-431.

101. Hasler WL. Traditional thoughts on the pathophysiology of irritable bowel syndrome. Gastroenterol Clin North Am 2011;40:2143.

102. Patacchini R, Santicioli P, Giuliani S, Maggi CA. Pharmacological investigation of hydrogen sulfide (H2S) contractile activity in rat detrusor muscle. Eur J Pharmacol 2005;509:171-177.

103. Weinstock LB, Klutke CG, Lin HC. Small intestinal bacterial overgrowth in patients with interstitial cystitis and gastrointestinal symptoms. Dig Dis Sci 2008;53:1246-1251.

104. Banik GD, De A, Som S, et al. Hydrogen sulphide in exhaled breath: a potential biomarker for small intestinal bacterial overgrowth in IBS. J Breath Res 2016;10:026010.

105. Pimentel M, Wallace D, Hallegua D, et al. A link between irritable bowel syndrome and fibromyalgia may be related to findings on lactulose breath testing. Ann Rheum Dis 2004;63:450-452.

106. Kwon JG, Park KS, Park JH, et al. Guidelines for the treatment of irritable bowel syndrome. Korean J Gastroenterol 2011;57:82-99.

107. Neale G, Gompertz D, Schönsby H, Tabaqchali S, Booth CC. The metabolic and nutritional consequences of bacterial overgrowth in the small intestine. Am J Clin Nutr 1972;25:1409-1417.

108. Scarpellini E, Gabrielli M, Lauritano CE, et al. High dosage rifaximin for the treatment of small intestinal bacterial overgrowth. Aliment Pharmacol Ther 2007;25:781-786.

109. Di Stefano M, Miceli E, Missanelli A, Corazza GR. Treatment of small intestine bacterial overgrowth. Eur Rev Med Pharmacol Sci 2005;9:217-222.

110. Quigley EM, Quera R. Small intestinal bacterial overgrowth: roles of antibiotics, prebiotics, and probiotics. Gastroenterology 
2006;130(2 Suppl1):S78-S90.

111. Chedid V, Dhalla S, Clarke JO, et al. Herbal therapy is equivalent to rifaximin for the treatment of small intestinal bacterial overgrowth. Glob Adv Health Med 2014;3:16-24.

112. Lauritano EC, Gabrielli M, Lupascu A, et al. Rifaximin dosefinding study for the treatment of small intestinal bacterial overgrowth. Aliment Pharmacol Ther 2005;22:31-35.

113. Pimentel M, Chow EJ, Lin HC. Normalization of lactulose breath testing correlates with symptom improvement in irritable bowel syndrome: a double-blind, randomized, placebo-controlled study. Am J Gastroenterol 2003;98:412-419.

114. Ghoshal UC, Srivastava D, Misra A, Ghoshal U. A proof-ofconcept study showing antibiotics to be more effective in irritable bowel syndrome with than without small-intestinal bacterial overgrowth: a randomized, double-blind, placebo-controlled trial. Eur J Gastroenterol Hepatol 2016;28:281-289.

115. Pimentel M, Lembo A, Chey WD, et al. Rifaximin therapy for patients with irritable bowel syndrome without constipation. N Engl J Med 2011;364:22-32.

116. Ford AC, Moayyedi P, Lacy BE, et al. American College of Gastroenterology monograph on the management of irritable bowel syndrome and chronic idiopathic constipation. Am J Gastroenterol 2014;109 Suppl 1:S2-S26.

117. Lacy BE, Chey WD, Lembo AJ. New and emerging treatment options for irritable bowel syndrome. Gastroenterol Hepatol (N Y) 2015;11(4 Suppl 2):1-19.

118. Weinberg DS, Smalley W, Heidelbaugh JJ, Sultan S; American Gastroenterological Association. American Gastroenterological Association Institute Guideline on the pharmacological management of irritable bowel syndrome. Gastroenterology 2014;147:1146-1148.

119. Attar A, Flourié B, Rambaud JC, Franchisseur C, Ruszniewski P, Bouhnik Y. Antibiotic efficacy in small intestinal bacterial overgrowth-related chronic diarrhea: a crossover, randomized trial. Gastroenterology 1999;117:794-797.

120. Gatta L, Scarpignato C. Mo2055 Rifaximin for treatment of small intestine bacterial overgrowth (SIBO): a systematic review and meta-analysis. Gastroenterology 2013;144(5 Suppl 1):S729.

121. Shah SC, Day LW, Somsouk M, Sewell JL. Meta-analysis: antibiotic therapy for small intestinal bacterial overgrowth. Aliment Pharmacol Ther 2013;38:925-934.

122. Lee BJ, Bak YT. Irritable bowel syndrome, gut microbiota and probiotics. J Neurogastroenterol Motil 2011;17:252-266.

123. Lacy BE, Weiser K, De Lee R. The treatment of irritable bowel syndrome. Therap Adv Gastroenterol 2009;2:221-238.

124. O'Mahony L, McCarthy J, Kelly P, et al. Lactobacillus and bifidobacterium in irritable bowel syndrome: symptom responses and relationship to cytokine profiles. Gastroenterology 2005;128:541551.

125. Thijssen AY, Jonkers D, Clemens CH, Masclee A. Effect of probiotic treatment on visceral hypersensitivity in irritable bowel syndrome. Gastroenterology 2011;140(5 Suppl 1):S852.
126. Lyszkowska M, Popinska K, Idzik M, Ksiazyk P. Probiotics in children with gut failure. J Pediatr Gastroenterol Nutr 2008;46:543.

127. Rosania R, Giorgio F, Principi M, et al. Effect of probiotic or prebiotic supplementation on antibiotic therapy in the small intestinal bacterial overgrowth: a comparative evaluation. Curr Clin Pharmacol 2013;8:169-172.

128. Kim HJ, Camilleri M, McKinzie S, et al. A randomized controlled trial of a probiotic, VSL\#3, on gut transit and symptoms in diarrhoea-predominant irritable bowel syndrome. Aliment Pharmacol Ther 2003;17:895-904.

129. Kim HJ, Vazquez Roque MI, Camilleri M, et al. A randomized controlled trial of a probiotic combination VSL\# 3 and placebo in irritable bowel syndrome with bloating. Neurogastroenterol Motil 2005;17:687-696.

130. Pimentel M, Soffer EE, Chow EJ, Kong Y, Lin HC. Lower frequency of MMC is found in IBS subjects with abnormal lactulose breath test, suggesting bacterial overgrowth. Dig Dis Sci 2002;47:2639-2643.

131. Pimentel M, Morales W, Lezcano S, Sun-Chuan D, Low K, Yang J. Low-dose nocturnal tegaserod or erythromycin delays symptom recurrence after treatment of irritable bowel syndrome based on presumed bacterial overgrowth. Gastroenterol Hepatol (N Y) 2009;5:435-442

132. Shepherd SJ, Halmos E, Glance S. The role of FODMAPs in irritable bowel syndrome. Curr Opin Clin Nutr Metab Care 2014;17:605609.

133. Halmos EP, Power VA, Shepherd SJ, Gibson PR, Muir JG. A diet low in FODMAPs reduces symptoms of irritable bowel syndrome. Gastroenterology 2014;146:67-75.e5.

134. Barrett JS, Gibson PR. Fermentable oligosaccharides, disaccharides, monosaccharides and polyols (FODMAPs) and nonallergic food intolerance: FODMAPs or food chemicals? Therap Adv Gastroenterol 2012;5:261-268.

135. Hayes PA, Fraher MH, Quigley EM. Irritable bowel syndrome: the role of food in pathogenesis and management. Gastroenterol Hepatol (N Y) 2014;10:164-174.

136. Ong DK, Mitchell SB, Barrett JS, et al. Manipulation of dietary short chain carbohydrates alters the pattern of gas production and genesis of symptoms in irritable bowel syndrome. J Gastroenterol Hepatol 2010;25:1366-1373.

137. Turnbaugh PJ, Ridaura VK, Faith JJ, Rey FE, Knight R, Gordon JI. The effect of diet on the human gut microbiome: a metagenomic analysis in humanized gnotobiotic mice. Sci Transl Med 2009;1:6ra14.

138. Brown K, DeCoffe D, Molcan E, Gibson DL. Diet-induced dysbiosis of the intestinal microbiota and the effects on immunity and disease. Nutrients 2012;4:1095-1119.

139. Zimmer J, Lange B, Frick JS, et al. A vegan or vegetarian diet substantially alters the human colonic faecal microbiota. Eur J Clin Nutr 2012;66:53-60.

140. Ghoshal UC, Singh R. Frequency and risk factors of functional gastro-intestinal disorders in a rural Indian population. J Gastroenterol 
Hepatol. Epub 2016 Jun 5. https://doi.org/10.1111/jgh.13465.

141. Drossman DA. Guidelines for use of the multi-dimensional clinical profile. In: Drossman DA, Azpiroz F, Chang L, et al., eds. Multi-dimensional clinical profile (MDCP): for functional gastrointestinal disorders. Raleigh: Rome Foundation, 2015:7-14.
142. Lindberg DA. Hydrogen breath testing in adults: what is it and why is it performed? Gastroenterol Nurs 2009;32:19-24.

143. Lombardo L, Foti M, Ruggia 0, Chiecchio A. Increased incidence of small intestinal bacterial overgrowth during proton pump inhibitor therapy. Clin Gastroenterol Hepatol 2010;8:504-508. 